\title{
Article \\ Color Index of Transformer Oil: A Low-Cost Measurement Approach Using Ultraviolet-Blue Laser
}

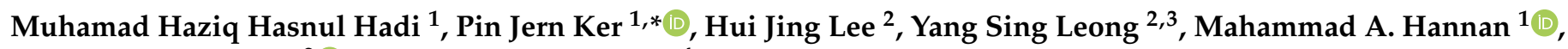 \\ Md. Zaini Jamaludin ${ }^{2}$ and Mohd Adzir Mahdi ${ }^{4}$ \\ 1 Institute of Sustainable Energy, Universiti Tenaga Nasional, Kajang 43000, Malaysia; \\ se23032@utn.edu.my (M.H.H.H.); hannan@uniten.edu.my (M.A.H.) \\ 2 Institute of Power Engineering, Universiti Tenaga Nasional, Kajang 43000, Malaysia; \\ LHjing@uniten.edu.my (H.J.L.); p107849@siswa.ukm.edu.my (Y.S.L.); mdzaini@uniten.edu.my (M.Z.J.) \\ 3 Department of Electrical, Electronic and System Engineering, Faculty of Engineering and Built \\ Environmental, Universiti Kebangsaan Malaysia (UKM), Bangi 43600, Malaysia \\ 4 Wireless and Photonics Networks Research Centre, Faculty of Engineering, Universiti Putra Malaysia (UPM), \\ Serdang 43400, Malaysia; mam@upm.edu.my \\ * Correspondence: pinjern@uniten.edu.my
}

Citation: Hasnul Hadi, M.H.; Ker, P.J.; Lee, H.J.; Leong, Y.S.; Hannan, M.A.; Jamaludin, M.Z.; Mahdi, M.A. Color Index of Transformer Oil: A Low-Cost Measurement Approach Using Ultraviolet-Blue Laser. Sensors 2021, 21, 7292. https://doi.org/ $10.3390 / \mathrm{s} 21217292$

Academic Editor: Steve Vanlanduit

Received: 22 September 2021

Accepted: 26 October 2021

Published: 2 November 2021

Publisher's Note: MDPI stays neutral with regard to jurisdictional claims in published maps and institutional affiliations.

\section{Copyright: (C) 2021 by the authors.} Licensee MDPI, Basel, Switzerland. This article is an open access article distributed under the terms and conditions of the Creative Commons Attribution (CC BY) license (https:// creativecommons.org/licenses/by/ $4.0 /)$.

\begin{abstract}
The color of transformer oil can be one of the first indicators determining the quality of the transformer oil and the condition of the power transformer. The current method of determining the color index $(\mathrm{CI})$ of transformer oil utilizes a color comparator based on the American Society for Testing and Materials (ASTM) D1500 standard, which requires a human observer, leading to human error and a limited number of samples tested per day. This paper reports on the utilization of ultra violet-blue laser at 405- and 450-nm wavelengths to measure the CI of transformer oil. In total, 20 transformer oil samples with CI ranging from 0.5 to 7.5 were measured at optical pathlengths of 10 and $1 \mathrm{~mm}$. A linear regression model was developed to determine the color index of the transformer oil. The equation was validated and verified by measuring the output power of a new batch of transformer oil samples. Data obtained from the measurements were able to quantify the CI accurately with root-mean-square errors (RMSEs) of 0.2229 for $405 \mathrm{~nm}$ and 0.4129 for $450 \mathrm{~nm}$. This approach shows the commercialization potential of a low-cost portable device that can be used on-site for the monitoring of power transformers.
\end{abstract}

Keywords: ASTM D1500; color; insulating oil; power transformers; single wavelength; transformer oil; ultraviolet-blue wavelength

\section{Introduction}

Power transformers are key assets of power utilities that ensure the regulation and distribution of electricity to housing and industrial areas. The insulation system is constantly exposed to electrical stress, mechanical stress, and thermal stress [1-4] during its operation. Lack of supervision of the condition of the transformer may cause catastrophic failures. In this regard, regular maintenance and monitoring of its insulation system are important to ensure their functionality is in an optimum condition. Conventionally, transformer oil is sampled from the power transformers and sent to an accredited laboratory for test analysis.

Early detection of transformer oil degradation is important through its color visualization since the quality of the transformer oil can be reflected by its color [5]. Color changes may be indicative of problems in the production process, contamination, degradation, or the oxidation of the materials and products. In addition, as the level of degradation of the transformer oil increases, the color of the transformer oil becomes darker [4]. Therefore, a faster approach for color measurement, which is cost effective and has high accuracy, is required. 
There are several available methods for measuring the color of liquid, such as visual examinations [6], color comparator [7], visual colorimeter [8-10], automatic colorimeter [11,12], optical spectroscopy [13-25], and image analysis [26-32]. The conventional method of measuring the color of transformer oil is to use a color comparator, where a sample is compared with a standard colored disc. The American Society for Testing and Materials (ASTM) D1500 is a standard color scale and test method for ASTM color of petroleum products including transformer oil. The ASTM color scale consists of 16 ASTM color indices ranging from 0.5 for the lightest color to 8.0 for the darkest color, with a 0.5 step size [7]. Operation wise, using a light source with a color temperature of $2750 \mathrm{~K}$, the sample in a standard glass jar is placed in the comparator, and it is compared with colored glass discs of the 16 ASTM color. If the color of the sample matches with any of the color disc, the color is reported. Otherwise, if the sample color is between two ASTM colors, the darker glass of the ASTM color preceded by the letter " $\mathrm{L}$ " is reported.

The optical spectroscopy technique has received increasing interest from researchers and industries as it is a non-destructive method. Through optical techniques, it eliminates human handling error and improves the measurement accuracy [13]. Researchers have used this method for measuring the color of palm oil [33,34], olive oil [25,35-38], honey [18-20,39], maple syrup [40,41], beer [21,22,42], and vegetable oils [15,16,43]. Specifically for transformer oil, Leong et al. [13] demonstrated the possibility of determining the color index (CI) of transformer oil in accordance with ASTM D1500 using ultraviolet (UV)-visible spectroscopy by measuring its optical absorbance at wavelengths from 300 to $700 \mathrm{~nm}$. The study shows that different color index of transformer oil can be accurately identified in the UV-visible waveband.

Although the UV-visible waveband has been used widely in the industries to measure the color of various types of oils, the basis of utilizing a single wavelength or a combination of a few wavelengths for color measurement of olive oil was first studied and reported by D. Escolar et al. [37]. Two absorbance measurements at 480 and $670 \mathrm{~nm}$ from a spectrophotometer were used to develop a mathematical model. The mathematical model was then used to estimate the chromatic coordinates and the chroma of olive oil based on the International Commission on Illumination (CIE) Lab values. Although this method does not exactly utilize a single-wavelength light source, the concept of measuring color using a single wavelength was exercised. Subsequently, R. Sanga et al. [44] managed to develop an in-line quasi-digital sensor system. This system utilizes two single-wavelength light-emitting diodes (LEDs) at 590 and $840 \mathrm{~nm}$ to measure the color and turbidity of lubricant oil. Two sets of optical systems were designed using two sets of light-dependent resistors (LDRs) and LEDs. One set was used to measure the color of the lubricant oil while another set was used to measure the turbidity and to correct the deviation in the color scale reading due to turbidity. An embedded system is required to convert the pulse frequency into the color scale. In comparison to other works on the utilization of a single wavelength for the determination of color, this system uses an LED, which has a broader spectrum across a wider waveband compared to a laser diode.

Previous works have shown that color measurement using a single wavelength is achievable. However, there is still no study on the color measurement of transformer oil using a single-wavelength laser diode in the UV-blue wavelength range. Figure 1 shows the absorbance spectrum for transformer oil samples with different color indices obtained from the measurement conducted by Leong et al. [13]. The measurement was carried out by using an ultraviolet-visible-near infrared (UV-Vis-NIR) spectrophotometer. They developed a mathematical model to determine the color index of transformer insulating oil using UV-visible spectroscopy with reference to the ASTM D1500 standard. Each color index has a different absorbance value throughout the UV-visible wavelength range. The color index is directly proportional to the absorbance value. 


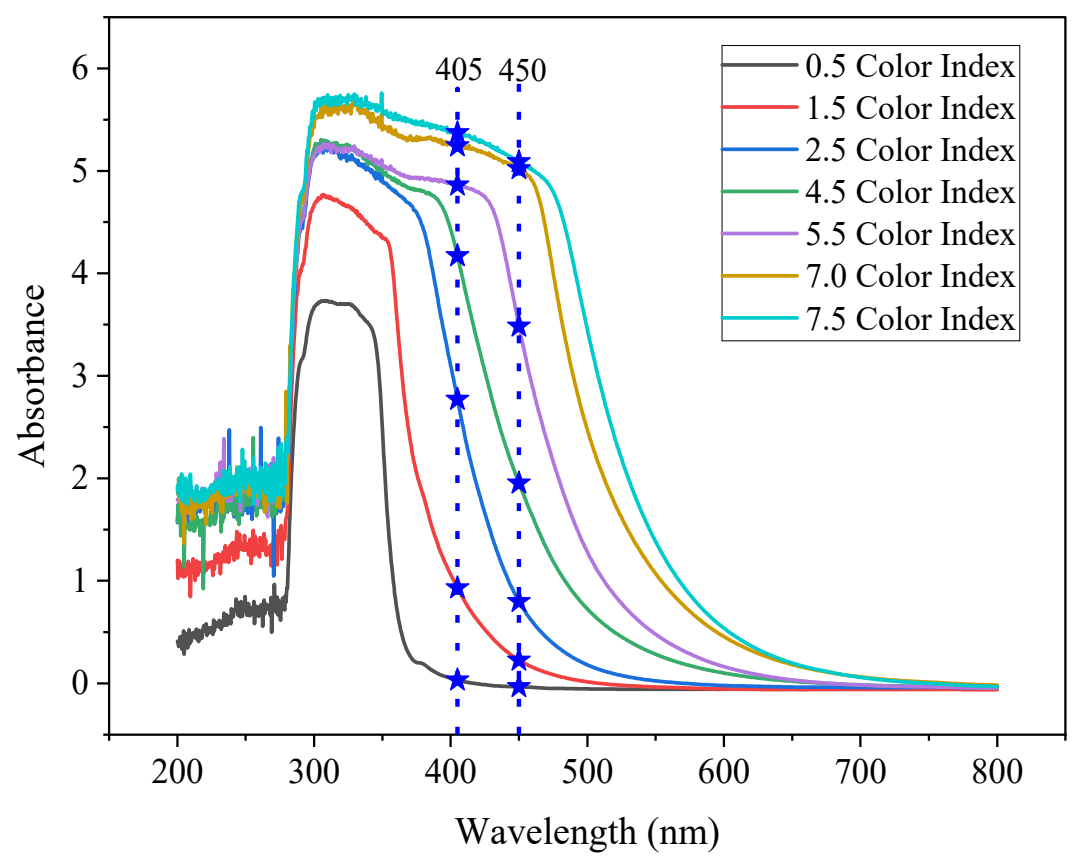

Figure 1. Optical absorbance spectrums for transformer oil samples based on ASTM D1500 and the possibility of using a single-wavelength laser diode.

It was observed that in the UV-blue waveband (400-500 nm), the absorbance values of the oil samples with different color indices are distinctly different. The blue dashed line shows the possibility of using a single-wavelength laser diode to determine the color index of transformer oil. The points on the blue dashed line that intercepts on the absorbance graph shows that each color index can be differentiated and measured using a single wavelength. Considering the availability of laser diodes at certain wavelengths, laser diodes at wavelengths of 405 and $450 \mathrm{~nm}$ were chosen as the light source because the absorbance of the oil sample can be distinctively determined.

Therefore, a comprehensive study was carried out to investigate the absorption of transformer oil samples with various color indices at wavelengths of 405 and $450 \mathrm{~nm}$. The correlation between the color index in accordance with the ASTM D1500 standard and the optical power output was established, and mathematical models were formulated. Critical comparisons between the proposed method and the other techniques were provided. The contributions of the study are as follows:

1. Utilization of a single-wavelength laser diode in the UV-blue wavelength for color index measurement of transformer oil was established.

2. Mathematical models were developed and validated to correlate the output power with the color index in accordance with ASTM D1500.

\section{Experimental Details}

In this study, transformer oil samples were collected, and their color indices were measured using a color comparator in accordance with the ASTM D1500 by an accredited lab. The oil samples were then tested, where the light beam from the single-wavelength laser diode passed through the oil sample and was detected by a photodiode sensor. The experimental setup for this study is shown in Figure 2. Light from the laser source was transmitted through the oil sample, which was placed in a quartz cuvette. The resulting optical signal was detected by the photodiode sensor. Table 1 shows the details and parameters of the components used in this experiment. 


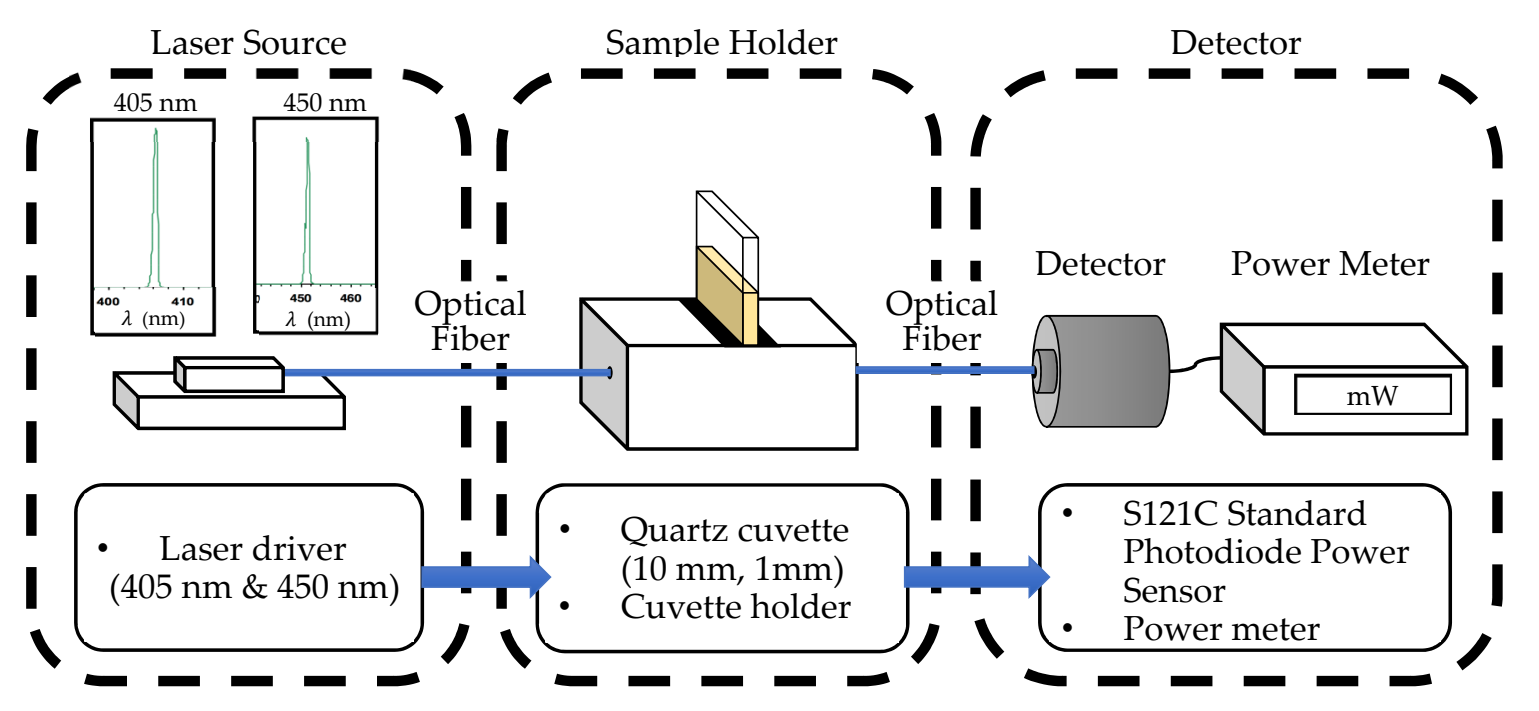

Figure 2. Schematics diagram of the components of the optical measuring setup.

Table 1. Components' details and parameters.

\begin{tabular}{ccc}
\hline Component & Details & Parameters \\
\hline \multirow{2}{*}{ Laser Diode } & $405 \mathrm{~nm}$ & Output Power: $20 \mathrm{~mW}$ \\
\cline { 2 - 3 } & $450 \mathrm{~nm}$ & Output Power: $50 \mathrm{~mW}$ \\
\hline \multirow{2}{*}{ Quartz Cuvette } & $10 \mathrm{~mm}$ & Volume: $3.5 \mathrm{~mL}$ \\
\cline { 2 - 3 } & $1 \mathrm{~mm}$ & Volume: $0.35 \mathrm{~mL}$ \\
\hline \multirow{2}{*}{ Detector } & & Material: Silicon \\
& Thorlabs S121C Standard & Range of Detection: \\
& Photodiode Power Sensor & Ro0 nm to $1100 \mathrm{~nm}$ \\
& & Responsivity: $<1 \mu \mathrm{s}$ \\
& & Sensitivity: $10 \mathrm{nW}$ \\
\hline
\end{tabular}

As shown in Figure 2, the setup is divided into three parts. The first part is the laser source. The laser diode is connected by fiber optic cable to the cuvette holder. Two commercially available laser diodes were used for the measurements and data collection. To ensure the consistency of the laser power, the laser diode was initially warmed up for $30 \mathrm{~min}$ at a constant operating temperature of $25^{\circ} \mathrm{C}$ before conducting the measurement. Both laser diodes were operated at the same operating voltage of $3.3 \mathrm{~V}$. For the $405-\mathrm{nm}$ laser diode, the output power was $20 \mathrm{~mW}$ while the output power of the 450-nm laser diode was $50 \mathrm{~mW}$. This difference in the output powers of the two laser diodes is due to the availability of the laser diode in the market. Although the output powers were different, measurements were made to observe whether higher output power can affect the results of the color measurement of transformer oil.

The second part of the setup is the sample holder. The sample holder is where the oil sample is located and is placed in a cuvette holder. Quartz cuvette cells with two different optical pathlengths of 10 and $1 \mathrm{~mm}$ were used in this experiment. This is to compare and to minimize the effect of optical pathlengths on the accuracy of the color index measurement. Before conducting the experiment, the oil sample was slowly pipetted into the cuvette cell to prevent the formation of bubbles. To ensure the consistency of the measurement, the sides of the cuvette were cleaned, such that there was no dust or fingerprints on the cuvette to allow optimum light interaction with the transformer oil samples.

In this experiment, 20 transformer oil samples with a color index ranging from 0.5 to 7.5 were used. However, a limited number of samples of only 1 or 2 oil samples were obtained for color index 4.5 and above. This is because the oil collected was from operating 
power transformers, where, according to the IEC 60422 standard, the oil needs to be replaced or maintained after reaching a certain threshold of color index. For the output power detection, a silicon photodiode was used. The amount of light detected by the sensor was measured using an optical power meter. To ensure the consistency of the reading collected, 5 readings were recorded at 10-s intervals. The average of the 5 readings was computed with a maximum error from $\pm 0.07 \%$ to $\pm 1.50 \%$.

\section{Results and Discussion}

Figure 3 shows the output power at wavelengths of 405 and $450 \mathrm{~nm}$ when oil samples with different color indices were measured using the $10-\mathrm{mm}$ pathlength cuvette. Based on the collected data, the output power decreases as the color index of the oil sample increases. The reduction of the output power, either at 405 or $450 \mathrm{~nm}$, was due to the optical absorption by the oil sample. The steeper decreasing slope for the measurement at $405 \mathrm{~nm}$ indicates that the measurement of the color index at this wavelength is more sensitive, compared to the measurement at $450 \mathrm{~nm}$. For the measurement at $405 \mathrm{~nm}(450 \mathrm{~nm})$, the output power saturated to almost zero for $\mathrm{CI} \geq 2$ ( $\mathrm{CI} \geq 3.5)$.

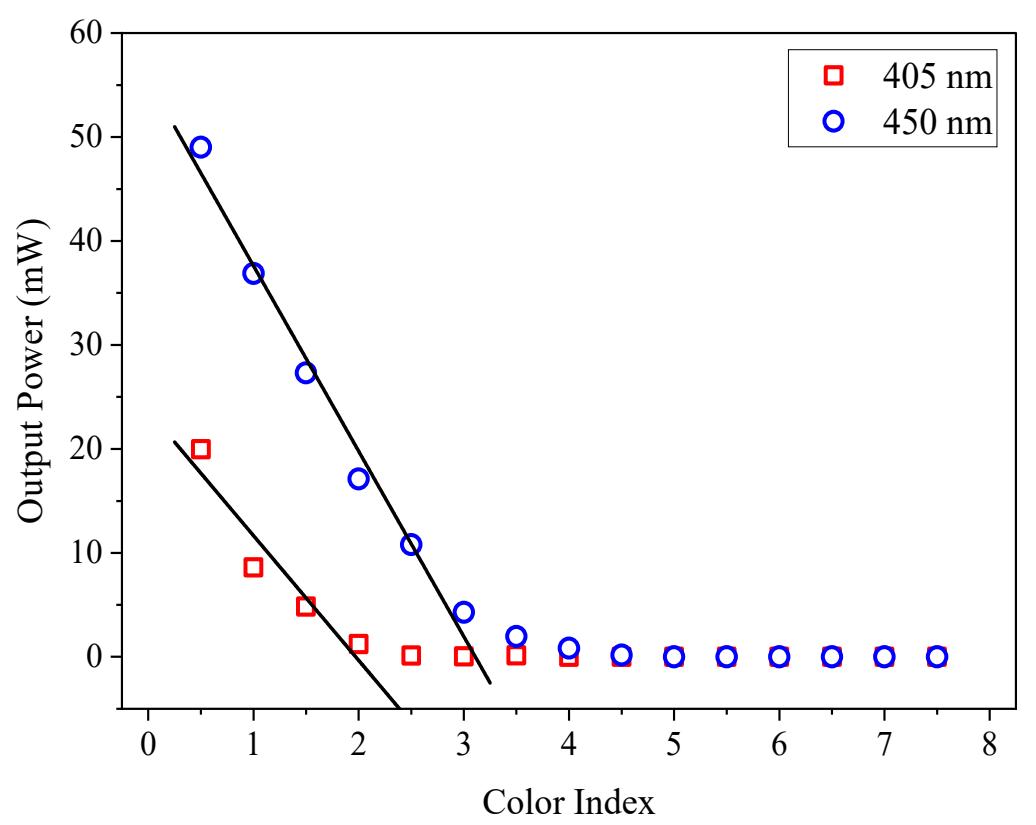

Figure 3. Measurement using laser diodes at wavelengths of 405 (input power $=24.7 \mathrm{~mW}$ ) and $450 \mathrm{~nm}$ (input power $=55.8 \mathrm{~mW}$ ) with a $10-\mathrm{mm}$ pathlength cuvette.

This saturation corresponds to the Beer-Lambert's law [45], where the loss of light intensity is directly proportional to the absorbance and length of the light path. In this case, the length of the light path, which is the cuvette pathlength, is long enough for most of the light to be absorbed by the transformer oil samples. Thus, this causes the output power to be saturated. The saturated $\mathrm{CI}$ was discarded because it does not represent the real measured values and only measurements up to $C I=1.5$ for $405 \mathrm{~nm}$, and $\mathrm{CI}=3.0$ for $450 \mathrm{~nm}$ were used for the linear regression. A linear decrement relationship can be observed between the color index and the output power when the saturated data was excluded. To measure the strength of the correlation between the variables, the Pearson product-moment correlation coefficient $(r)$ of the data was calculated. The $r$ value indicates the strength and the trend line direction of the linear relationship between the two variables. The calculated $r$ values between the color index and output power in Figure 3 is -0.9539 for $405 \mathrm{~nm}$ and -0.9925 for $450 \mathrm{~nm}$. Table 2 shows the guideline to determine the strength of the correlation relationship for absolute value of $r(|r|)$. In both cases, since $|r|>0.95$, the strength of linear correlation is considered very strong. 
Table 2. The interpretation of the strength of the relationship for absolute values of correlation.

\begin{tabular}{cc}
\hline Absolute Value of $\boldsymbol{r},|\boldsymbol{r}|$ & Strength of Relationship \\
\hline $0-0.19$ & Very weak \\
$0.20-0.39$ & Weak \\
$0.40-0.59$ & Moderate \\
$0.60-0.79$ & Strong \\
$0.80-1.00$ & Very strong \\
\hline
\end{tabular}

The negative $r$ value indicates a negative correlation between the color index and output power. The two correlation coefficient show a very strong linear correlation as the absolute values of $r$ are very close to 1 .

Although measurement using $10 \mathrm{~mm}$ was saturated at a certain CI, a linear regression line was done on the unsaturated data points and the regression model was used to calculate the CI. Table 3 shows the linear equations obtained from the regression model.

Table 3. Linear equation and $\mathrm{R}^{2}$ for measurement using the $10-\mathrm{mm}$ pathlength cuvette.

\begin{tabular}{ccccc}
\hline Wavelength $\mathbf{( n m )}$ & Equation & Intercept, $\boldsymbol{a}$ & Slope, $\boldsymbol{b}$ & $\mathbf{R}^{\mathbf{2}}$ \\
\hline 405 & $y=a+b \times x$ & 26.269 & -15.133 & 0.92277 \\
450 & & 55.438 & -17.830 & 0.98497 \\
\hline
\end{tabular}

Nevertheless, to ensure that the measurement can be done for the full range of $\mathrm{CI}$ ( 0.5 to 7.5) based on the ASTM D1500 standard, a cuvette with a shorter pathlength of $1 \mathrm{~mm}$ was used. The interaction of light with the oil sample was shortened, thus reducing the light absorbance.

Data collected from the measurement using the 1-mm pathlength cuvette are plotted in Figure 4. The $r$ values for the data points in Figure 4 were also calculated. The $r$ values for the data points of 405 and $450 \mathrm{~nm}$ are -0.99958 and -0.986 , respectively, which also show a very strong linear correlation. The data points for the measurements were fitted with a linear regression model that described the relationship of the data. The linear regression model obtained from the plotted data points for the CI measurement at 405 and $450 \mathrm{~nm}$ is shown in Table 4.

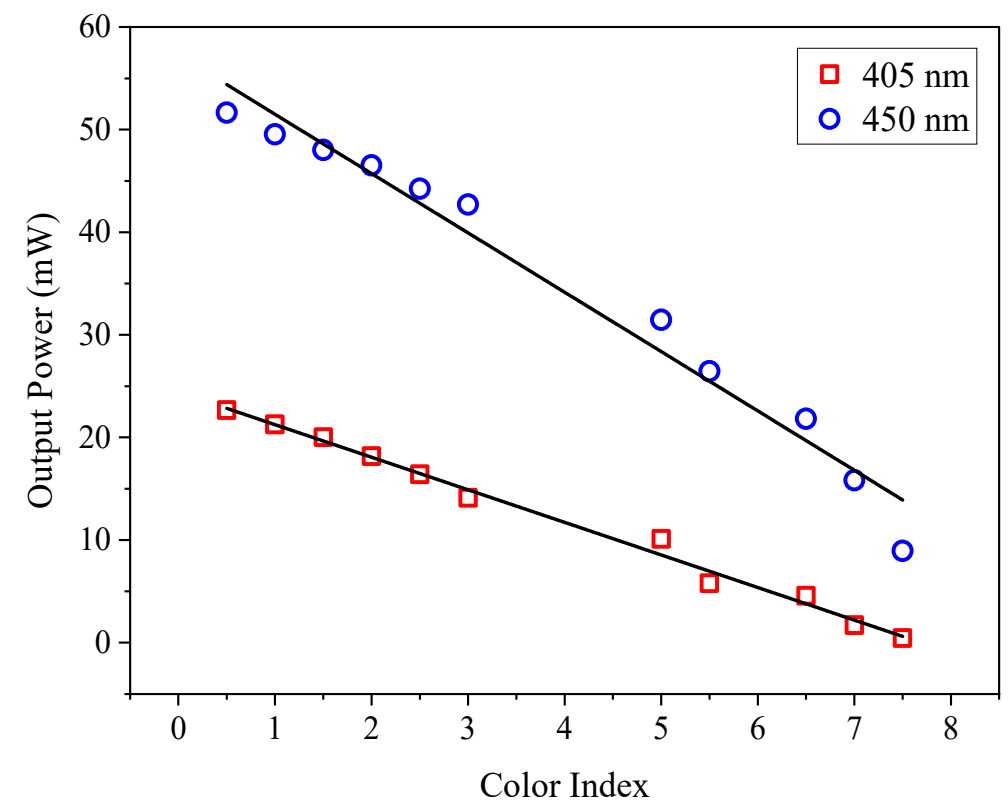

Figure 4. Measurement using the 405-nm laser diode (input power $=24.4 \mathrm{~mW}$ ) and 450-nm laser diode (input power $=54.7 \mathrm{~mW}$ ) with a $1-\mathrm{mm}$ pathlength cuvette. 
Table 4. Linear equation and $\mathrm{R}^{2}$ for measurements using the 1-mm pathlength cuvette.

\begin{tabular}{ccccc}
\hline Wavelength $\mathbf{( n m )}$ & Equation & Intercept, $\boldsymbol{a}$ & Slope, $\boldsymbol{b}$ & $\mathbf{R}^{\mathbf{2}}$ \\
\hline 405 & $y=a+b \times x$ & 24.421 & -3.1745 & 0.99168 \\
450 & 57.284 & -5.7831 & 0.97202 \\
\hline
\end{tabular}

The equations were rearranged as follows to determine the color index:

$$
\begin{aligned}
C I_{405} & =\frac{\text { Output Power }-24.421}{(-3.1745)} \\
C I_{450} & =\frac{\text { Output Power }-57.285}{(-5.7832)}
\end{aligned}
$$

where $x$ is the $C I$ and $y$ is the Output Power measured.

The linear regression line on the data obtained from measurements at $405 \mathrm{~nm}$ has an $R^{2}$ value of 0.99168 , while measurement with the $450-\mathrm{nm}$ laser diode has an $R^{2}$ value of 0.97202. Based on Table 4, the slope for $450 \mathrm{~nm}$ is steeper than $405 \mathrm{~nm}$. The steeper slope indicates that the absorbance value increased more significantly at $450 \mathrm{~nm}$ as the color index increased. However, the data distribution measured at $405 \mathrm{~nm}$ has better linearity compared to that measured at $450 \mathrm{~nm}$. This was because the absorbance value increased consistently with the increasing color index as shown in Figure 1. At $450 \mathrm{~nm}$, the increment in the absorbance value with the increasing color index was not consistent. The increments in the absorbance value for low ( 0.5 to 1.5$)$ and high (7.0 and 7.5) color indices were smaller, compared to those at $2.0 \leq C I \leq 6.5$. Therefore, $405 \mathrm{~nm}$ gave a better regression line fitting, which led to a better $R^{2}$ value.

To validate the mathematical models of Equations (1) and (2), a new set of transformer oil samples (S1-S11) were collected from the accredited laboratory, with their results on the color indices in accordance with the ASTM D1500 standard. However, since a transformer oil sample with a higher color index was difficult to obtain, a few samples were reused to validate the equation. The repeating samples were S8-S11. The oil samples were measured for their output power at 405 and $450 \mathrm{~nm}$ with a 1-mm pathlength cuvette. The estimated $C I$ was calculated using Equations (1) and (2). The difference between the actual CI obtained from the ASTM D1500 measurement and the estimated CI using the developed model was then calculated and analyzed.

Based on Table 5, the result shows that the estimated CI for each sample using Equation (1) was closer to the actual CI compared to the estimated CI using Equation (2). The root-meansquare error (RMSE) values were calculated and compared for Equations (1) and (2). RMSE defines the standard deviation of the difference between the actual value and estimated value. The error from RMSE was possibly due to the measurement process, and the model developed. The error could also be due to the measurement from the conventional method of the ASTM D1500 standard. Through RMSE, the variation of the actual data near the regression line can be identified.

Theoretically, based on Figure 1, measurement at $450 \mathrm{~nm}$ should be able to predict the $C I$ for samples with high $C I$ more accurately than measurement at $405 \mathrm{~nm}$. This is because the differences in absorbance for the higher color index at $450 \mathrm{~nm}$ is bigger than that at $405 \mathrm{~nm}$. However, the difference in CI for S5, S6, S7, S9, S10, and S11 in Table 5 showed otherwise as the estimated CI using Equation (2) has a bigger difference in CI. It is also shown that the RMSE for Equation (1) is 0.2229, which is lower compared to RMSE for Equation (2), which has an RMSE of 0.4129. Compared to the ASTM D1500 standard, which has an error of $\leq 0.5$ due to the method of reporting, the RMSE of 0.4129 using Equation (2) is within the acceptable range of error, although it was higher than that obtained from Equation (1). 
Table 5. Comparison between ASTM D1500 standard, and estimated color index using Equations (1) and (2).

\begin{tabular}{|c|c|c|c|c|c|}
\hline & Sample & $\begin{array}{c}\text { ASTM } \\
\text { D1500 }\end{array}$ & Estimated CI & $\begin{array}{l}\text { Difference } \\
\text { in CI }\end{array}$ & RMSE \\
\hline \multirow{11}{*}{$\begin{array}{c}\text { Equation (1) } \\
\quad I_{405} \\
\left(\mathrm{R}^{2}=0.99170\right)\end{array}$} & S1 & 0.5 & 0.55 & 0.05 & \multirow{11}{*}{0.2229} \\
\hline & S2 & 1.0 & 0.99 & -0.01 & \\
\hline & S3 & 1.5 & 1.39 & -0.11 & \\
\hline & S4 & 2.0 & 1.97 & -0.03 & \\
\hline & S5 & 2.5 & 2.52 & 0.02 & \\
\hline & S6 & 3.0 & 3.25 & 0.25 & \\
\hline & S7 & 5.0 & 4.50 & -0.50 & \\
\hline & S8 & 5.5 & 5.87 & 0.37 & \\
\hline & S9 & 6.5 & 6.26 & -0.24 & \\
\hline & S10 & 7.0 & 7.15 & 0.15 & \\
\hline & $\mathrm{S} 11$ & 7.5 & 7.55 & 0.05 & \\
\hline \multirow{11}{*}{$\begin{array}{c}\text { Equation (2) } \\
\quad I_{450} \\
\left(\mathrm{R}^{2}=0.97200\right)\end{array}$} & S1 & 0.5 & 0.97 & 0.47 & \multirow{11}{*}{0.4129} \\
\hline & S2 & 1.0 & 1.34 & 0.34 & \\
\hline & S3 & 1.5 & 1.60 & 0.10 & \\
\hline & S4 & 2.0 & 1.86 & -0.14 & \\
\hline & S5 & 2.5 & 2.25 & -0.25 & \\
\hline & S6 & 3.0 & 2.52 & -0.48 & \\
\hline & S7 & 5.0 & 4.46 & -0.54 & \\
\hline & S8 & 5.5 & 5.33 & -0.17 & \\
\hline & S9 & 6.5 & 6.13 & -0.37 & \\
\hline & S10 & 7.0 & 7.17 & 0.17 & \\
\hline & S11 & 7.5 & 8.36 & 0.86 & \\
\hline
\end{tabular}

CI-Color index.

The RMSE value (0.2229) obtained from this work was slightly higher compared to the RMSE (0.1961) obtained by Leong et al. [13]. However, this work utilized data obtained from a single wavelength while Leong et al. [13] relied on data obtained from 350 to $700 \mathrm{~nm}$ and correlated the $C I$ with the cutoff wavelengths from the absorbance spectrum and absorbance of the oil samples. The conventional method of measuring the color index according to ASTM D1500 relies on manual visual inspection by an operator, which limits the number of measurements per day. This conventional method also depends on the operator's perception of colors, which can lead to human error. Other than that, the color scale contains a large step size of $0.5 \mathrm{CI}$, which can result in higher error of the color index. This shows that measurement using a single-wavelength laser diode produced a sufficiently small error with a simpler measurement setup.

To elucidate the effect of the optical pathlength on the accuracy of $C I$ measurement, repeating samples were used for the validation of the regression models (refer to Tables 3 and 4) using 10- and 1-mm cuvettes. The estimated CI values using the regression models are shown in Table 6. The measurement at both wavelengths using the 10-mm pathlength showed good RMSE values of 0.1181 and 0.1055 .

A comparison between measurements using the 10- and 1-mm pathlengths is shown in Table 6. Repeating samples were used for this comparison. At $450 \mathrm{~nm}$, the utilization of the 10-mm pathlength cuvette improved the RMSE significantly from 0.3309 to 0.1055. However, the RMSE obtained for measurements at $405 \mathrm{~nm}$ with the 10- and 1-mm pathlengths were comparable. This shows that measuring different $C I$ (from 0.5 to 8.0 ) at the optimum optical pathlength is important in minimizing the measurement error. 
Table 6. Comparison of the estimated CI between the 10-mm pathlength cuvette and 1-mm pathlength cuvette.

\begin{tabular}{|c|c|c|c|c|c|c|c|c|}
\hline \multirow{3}{*}{ Wavelength } & \multirow{3}{*}{ Sample } & \multirow{3}{*}{$\begin{array}{c}\text { ASTM } \\
\text { D1500 }\end{array}$} & \multicolumn{6}{|c|}{ Cuvette } \\
\hline & & & \multicolumn{3}{|c|}{$10 \mathrm{~mm}$} & \multicolumn{3}{|c|}{$1 \mathrm{~mm}$} \\
\hline & & & $\begin{array}{c}\text { Estimated } \\
\qquad I I\end{array}$ & Difference & RMSE & $\begin{array}{c}\text { Estimated } \\
\qquad I I\end{array}$ & Difference & RMSE \\
\hline \multirow{3}{*}{405} & S1 & 0.5 & 0.42 & -0.08 & \multirow{3}{*}{0.1181} & 0.55 & 0.05 & \multirow{3}{*}{0.0728} \\
\hline & $\mathrm{S} 2$ & 1.0 & 1.17 & 0.17 & & 0.99 & -0.01 & \\
\hline & S3 & 1.5 & 1.42 & -0.08 & & 1.39 & -0.11 & \\
\hline \multirow{6}{*}{450} & S1 & 0.5 & 0.36 & -0.14 & \multirow{6}{*}{0.1055} & 0.97 & 0.47 & \multirow{6}{*}{0.3309} \\
\hline & S2 & 1.0 & 1.04 & 0.04 & & 1.34 & 0.34 & \\
\hline & S3 & 1.5 & 1.58 & 0.08 & & 1.60 & 0.10 & \\
\hline & $\mathrm{S} 4$ & 2.0 & 2.15 & 0.15 & & 1.86 & -0.14 & \\
\hline & S5 & 2.5 & 2.50 & 0.00 & & 2.25 & -0.25 & \\
\hline & S6 & 3.0 & 2.87 & -0.13 & & 2.52 & -0.48 & \\
\hline
\end{tabular}

Table 7 presents a summary of the methods and techniques for color index measurement of transformer oil. The results demonstrated that the utilization of a singlewavelength laser diode in the UV-blue wavelength in determining the CI of transformer oil based on ASTM D1500 can provide better sensitivity up to $0.1 \mathrm{CI}$. Human handling error can also be eliminated as it does not require a human observer for the color identification process. In comparison with previous work that utilizes the full spectrum from 350 to $700 \mathrm{~nm}$, this work requires only a single-wavelength optical source, which simplifies the optoelectronic components significantly.

Table 7. Comparison of methods for color index measurement of transformer oil.

\begin{tabular}{ccccc}
\hline Methods & Wavelength $(\mathbf{n m})$ & Human Observation & Model Equation & Accuracy \\
\hline ASTM D1500 standard & NA & $\checkmark$ & $\times$ & Max. error of 0.5 is tolerated \\
UV-Vis Spectroscopy & $300-700$ & $\times$ & $\checkmark$ & RMSE $=0.1961$ \\
Single wavelength & 405 & $\times$ & $\checkmark$ & RMSE $_{405}=0.2229$ \\
spectroscopy & 450 & $\times$ & $\checkmark$ & RMSE $_{450}=0.4129$ \\
\hline
\end{tabular}

\section{Conclusions}

This work shows that the color index of transformer oil can be measured using a singlewavelength optical source. Based on the ASTM D1500 standard, linear regression models were developed to accurately determine the color index of transformer oil using the data obtained from measurements at 405 and $450 \mathrm{~nm}$. Model validation using a second batch of oil samples showed that the models were able to determine the color index accurately, with RMSE values of 0.2229 and 0.4129 for data measured at 405 and $450 \mathrm{~nm}$, respectively. The results of this work demonstrate that UV-blue wavelengths at 405 and $450 \mathrm{~nm}$ can be used for the determination of the color index of transformer oil. Unlike previous work that requires a spectrophotometer for measurements of the full spectrum from 350 to $700 \mathrm{~nm}$, the utilization of a single wavelength promises a much-simplified portable device for the color measurement of transformer oil. Although the measurement using either 405 or $450 \mathrm{~nm}$ can provide accurate color measurement of transformer oil, it is hypothesized that a hybrid of both wavelengths may lead to better accuracy. While this work has clearly demonstrated the possibility of utilizing single-wavelength measurement to determine the color index of transformer oil, the following future works are proposed to achieve higher accuracy:

1. A detailed study on the effect of optical pathlength variation and more accurate color index measurement.

2. An investigation of the optimum laser power required for a particular color index to ensure that transformer oil with the full range of the color index can be measured. 
3. Due to the variations of optical pathlengths and optimum laser powers, a machine learning-based model can be developed to more accurately model the color index of transformer oil based on multiple inputs.

Author Contributions: This work was mainly conducted by M.H.H.H. and he composed the manuscript. P.J.K., Y.S.L. and M.A.M. contributed their effort to designing the experimental setup, result analysis, and manuscript revision. M.A.H., M.Z.J. and H.J.L. provided access to the laboratory equipment, facilities, and oil samples from power transformers. All authors have read and agreed to the published version of the manuscript.

Funding: This research was funded by the Fundamental Research Grant Scheme (FRGS) by the Malaysian Ministry of Higher Education with the project code: FRGS/1/2020/TK0/UNITEN/02/6 (20210111FRGS) and Internal Grant by Universiti Tenaga Nasional (UNITEN) (Project code: J510050002/ 2021019). The APC was funded by UNITEN Bold Refresh Publication Fund 2021, under Project J5100D4103.

Institutional Review Board Statement: Not applicable.

Informed Consent Statement: Not applicable.

Data Availability Statement: Not applicable.

Acknowledgments: The authors acknowledge the support received from Universiti Tenaga Nasional (UNITEN), Universiti Putra Malaysia (UPM), and TNB Labs Sdn. Bhd. Transformer Oil Lab for the access to the laboratory equipment and facilities, and transformer oil samples.

Conflicts of Interest: The authors declare no conflict of interest.

\section{References}

1. Jan, S.T.; Afzal, R.; Khan, A.Z. Transformer Failures, Causes \& Impact. In Proceedings of the International Conference Data Mining, Civil and Mechanical Engineering (ICDMCME'2015), Bali, Indonesia, 1-2 February 2015; pp. 49-52. [CrossRef]

2. Alshehawy, A.M.; Mansour, D.E.A.; Rezk, A.; Ghali, M. Impact of thermal aging of transformer oil on UV-Vis optical spectrum and dielectric properties. In Proceedings of the 2016 Eighteenth International Middle East Power Systems Conference (MEPCON), Cairo, Egypt, 27-29 December 2016; pp. 860-865. [CrossRef]

3. Karmakar, S.; Roy, N.K.; Kumbhakar, P. Effect of ageing in transformer oil using UV-visible spectrophotometeric technique. J. Opt. 2011, 40, 33-38. [CrossRef]

4. Kalathiripi, H.; Karmakar, S. Analysis of transformer oil degradation due to thermal stress using optical spectroscopic techniques. Int. Trans. Electr. Energy Syst. 2017, 27, 1-11. [CrossRef]

5. Sylvestre N'cho, J.; Fofana, I.; Hadjadj, Y.; Beroual, A. Review of physicochemical-based diagnostic techniques for assessing insulation condition in aged transformers. Energies 2016, 9, 367. [CrossRef]

6. Totani, N.; Tateishi, S.; Chiue, H.; Mori, T. Color and chemical properties of oil used for deep frying on a large scale. J. Oleo Sci. 2012, 61, 121-126. [CrossRef]

7. ASTM International United States. ASTM International United States Standard Test Method for ASTM Color of Petroleum Products (ASTM Color Scale) 1. Annu. B. ASTM Stand. 2011, 5, 1-5. [CrossRef]

8. Fernandes, S.S.; Tonato, D.; Mazutti, M.A.; de Abreu, B.R.; da Costa Cabrera, D.; D'Oca, C.D.R.M.; Prentice-Hernández, C.; Salas-Mellado, M.D.L.M. Yield and quality of chia oil extracted via different methods. J. Food Eng. 2019, 262, 200-208. [CrossRef]

9. Sulaiman, N.S.; Mohd-Yusof, K.; Mohd-Saion, A. Quality prediction modeling of palm oil refining plant in Malaysia using artificial neural network models. Int. J. Eng. Technol. 2018, 7, 19-22. [CrossRef]

10. Shen, Y.; Zheng, L.; Jin, J.; Li, X.; Fu, J.; Wang, M.; Guan, Y.; Song, X. Physicochemical and biological characteristics of Mexican chia seed oil. Molecules 2018, 23, 3219. [CrossRef]

11. Timilsena, Y.P.; Vongsvivut, J.; Adhikari, R.; Adhikari, B. Physicochemical and thermal characteristics of Australian chia seed oil. Food Chem. 2017, 228, 394-402. [CrossRef]

12. El-Naggar, E.A. Physicochemical Characteristics of Tiger Nut Tuber (Cyperus esculentus Lam) Oil. Middle East J. Appl. Sci. 2016, 6, 1003-1011.

13. Leong, Y.S.; Ker, P.J.; Jamaludin, M.Z.; Nomanbhay, S.M.; Ismail, A.; Abdullah, F.; Looe, H.M.; Lo, C.K. UV-vis spectroscopy: A new approach for assessing the color index of transformer insulating oil. Sensors 2018, 18, 2175. [CrossRef] [PubMed]

14. Sing, L.Y.; Ker, P.J.; Jamaludin, M.Z.; Ismail, A.; Abdullah, F.; Mun, L.H.; Saniyyat, C.N.; Shukri, M. Determining the inhibitor content of transformer insulating oil using UV-Vis spectroscopy. In Proceedings of the 2016 6th IEEE International Conference on Control System, Computing and Engineering (ICCSCE), Penang, Malaysia, 25-27 November 2016; pp. 179-183. [CrossRef]

15. Muzzio, C.R.; Díaz, R.J.; Dini, N.G. In-line measurement of sunflower oil color in the Lovibond scale using a low-cost robust device. J. Food Eng. 2014, 120, 88-93. [CrossRef] 
16. Liaotrakoon, W.; Namhong, T.; Yu, C.H.; Chen, H.H. Impact of roasting on the changes in composition and quality of cashew nut (Anacardium occidentale) oil. Int. Food Res. J. 2016, 23, 986-991.

17. Sandulachi, E.; Tatarov, P. Photometric color index of walnut oil. In Proceedings of the International Conference MTFI-2014, Modern Technologies in the Food Industry, Chişinau, Moldova, 16-18 October 2014; pp. 281-286.

18. Al-Farsi, M.; Al-Amri, A.; Al-Hadhrami, A.; Al-Belushi, S. Color, flavonoids, phenolics and antioxidants of Omani honey. Heliyon 2018, 4, e00874. [CrossRef]

19. Moniruzzaman, M.; Yung An, C.; Rao, P.V.; Hawlader, M.N.I.; Azlan, S.A.B.M.; Sulaiman, S.A.; Gan, S.H. Identification of phenolic acids and flavonoids in monofloral honey from bangladesh by high performance liquid chromatography: Determination of antioxidant capacity. Biomed Res. Int. 2014, 2014, 1-11. [CrossRef]

20. Szabó, R.T.; Mézes, M.; Szalai, T.; Zajácz, E.; Weber, M. Colour identification of honey and methodical development of its instrumental measuring. Columella J. Agric. Environ. Sci. 2016, 3. [CrossRef]

21. Di Caro, D.; Liguori, C.; Pietrosanto, A.; Sommella, P. A low-cost device for beer color measurement. In Proceedings of the 2019 IEEE International Workshop on Metrology for Agriculture and Forestry (MetroAgriFor), Portici, Italy, 24-26 October 2019; pp. 222-226. [CrossRef]

22. Koren, D.; Hegyesné Vecseri, B.; Kun-Farkas, G.; Urbin, Á.; Nyitrai, Á.; Sipos, L. How to objectively determine the color of beer? J. Food Sci. Technol. 2020, 57, 1183-1189. [CrossRef]

23. Salem, S.; Salem, A.; Agha Babaei, A. Preparation and characterization of nano porous bentonite for regeneration of semi-treated waste engine oil: Applied aspects for enhanced recovery. Chem. Eng. J. 2015, 260, 368-376. [CrossRef]

24. Ossia, C.V.; Hosung, K.; Markova, L.V. Utilization of color change in the condition monitoring of synthetic hydraulic oils. Ind. Lubr. Tribol. 2010, 62, 349-355. [CrossRef]

25. Salmerón, J.F.; Gómez-Robledo, L.; Carvajal, M.Á.; Huertas, R.; Moyano, M.J.; Gordillo, B.; Palma, A.J.; Heredia, F.J.; Melgosa, M. Measuring the colour of virgin olive oils in a new colour scale using a low-cost portable electronic device. J. Food Eng. 2012, 111, 247-254. [CrossRef]

26. Dominguez, M.A.; Centurión, M.E. Application of digital images to determine color in honey samples from Argentina. Microchem. J. 2015, 118, 110-114. [CrossRef]

27. Ishak, A.J.; Abdul Rahman, R.Z.; Soh, A.C.; Shamsudin, R.; Jalo, S.A.; Lim, F.C.; Lin, H.K. Quality identification of used cooking oil based on feature fusion of gas sensor and color. Int. J. Control. Theory Appl. 2016, 9, 2405-2413.

28. Shafiee, S.; Minaei, S.; Moghaddam-Charkari, N.; Ghasemi-Varnamkhasti, M.; Barzegar, M. Potential application of machine vision to honey characterization. Trends Food Sci. Technol. 2013, 30, 174-177. [CrossRef]

29. Anacan, R.M.; Cabautan, A.C.; Cayabyab, J.M.A.; Miguel, S.X.A.; Modrigo, V.D.; Rosites, C.J.V.; Sagun, A.C. Development of oil quality estimator using machine vision system. In Proceedings of the 2018 IEEE 10th International Conference on Humanoid, Nanotechnology, Information Technology, Communication and Control, Environment and Management (HNICEM), Baguio City, Philippines, 29 November-2 December 2018; pp. 1-6. [CrossRef]

30. Araújo, P.D.; Moya, M.V.M.; De Paula, I.C. Classification of cotton oil in the semi-refining process using image processing techniques: Image processing for industrial applications. In Proceedings of the 2017 Seventh International Conference on Innovative Computing Technology (INTECH), Luton, UK, 16-18 August 2017; pp. 21-25. [CrossRef]

31. Nikolova, K.T.; Gabrova, R.; Boyadzhiev, D.; Pisanova, E.S.; Ruseva, J.; Yanakiev, D. Classification of different types of beer according to their colour characteristics. J. Phys. Conf. Ser. 2017, 794, 012035. [CrossRef]

32. Silva, T.C.O.; Godinho, M.S.; de Oliveira, A.E. Identification of pale lager beers via image analysis. Lat. Am. Appl. Res. 2011, 41, 141-145.

33. Mannu, A.; Vlahopoulou, G.; Sireus, V.; Petretto, G.L.; Mulas, G.; Garroni, S. Bentonite as a refining agent in waste cooking oils recycling: Flash point, density and color evaluation. Nat. Prod. Commun. 2018, 13, 613-616. [CrossRef]

34. Tan, Y.A.; Kuntom, A.; Lee, C.K.; Low, K.S. Comparative evaluation of palm oil color measurement using a prototype palm oil colorimeter. J. Am. Oil Chem. Soc. 2004, 81, 733-736. [CrossRef]

35. Moyano, M.J.; Heredia, F.J.; Meléndez-Martínez, A.J. The color of olive oils: The pigments and their likely health benefits and visual and instrumental methods of analysis. Compr. Rev. Food Sci. Food Saf. 2010, 9, 278-291. [CrossRef]

36. Gómez-Robledo, L.; Melgosa, M.; Huertas, R.; Roa, R.; Moyano, M.J.; Heredia, F.J. Virgin-olive-oil color in relation to sample thickness and the measurement method. J. Am. Oil Chem. Soc. 2008, 85, 1063-1071. [CrossRef]

37. Escolar, D.; Haro, M.R.; Ayuso, J. An efficient method for a numerical description of virgin olive oil color with only two absorbance measurements. J. Am. Oil Chem. Soc. 2002, 79, 769-774. [CrossRef]

38. Moyano, M.J.; Ayala, F.; Echávarri, J.F.; Alba, J.; Negueruela, A.I.; Heredia, F.J. Simplified measurement of virgin olive oil color by application of the characteristic vector method. J. Am. Oil Chem. Soc. 2001, 78, 1221-1226. [CrossRef]

39. Kuś, P.M.; Congiu, F.; Teper, D.; Sroka, Z.; Jerković, I.; Tuberoso, C.I.G. Antioxidant activity, color characteristics, total phenol content and general HPLC fingerprints of six Polish unifloral honey types. LWT-Food Sci. Technol. 2014, 55, 124-130. [CrossRef]

40. Filteau, M.; Lagacé, L.; LaPointe, G.; Roy, D. Maple sap predominant microbial contaminants are correlated with the physicochemical and sensorial properties of maple syrup. Int. J. Food Microbiol. 2012, 154, 30-36. [CrossRef] [PubMed]

41. Aider, M.; de Halleux, D.; Belkacemi, K. Production of granulated sugar from maple syrup with high content of inverted sugar. $J$. Food Eng. 2007, 80, 791-797. [CrossRef] 
42. Mignani, A.G.; Ciaccheri, L.; Mencaglia, A.A.; Ottevaere, H.; Baća, E.E.S.; Thienpont, H. Optical measurements and patternrecognition techniques for identifying the characteristics of beer and distinguishing Belgian beers. Sens. Actuators B Chem. 2013, 179, 140-149. [CrossRef]

43. Megahed, M. Effect of microwave heating of linseed oil on the formation of primary and secondary oxidation products. Agric. Biol. J. N. Am. 2011, 2, 673-679. [CrossRef]

44. Sanga, R.; Sivaramakrishna, M.; Srinivasan, V.S.; Prabhakara Rao, G. Design and Development of Opto-Resistive Type QuasiDigital Sensor and Instrument for Online Assessment of the Quality of Lubricant Oil. IEEE Sens. J. 2019, 19, 7499-7506. [CrossRef]

45. Mitschele, J. Beer-Lambert Law. J. Chem. Educ. 1996, 73, A260. [CrossRef] 